\title{
Magnetic Hydrodynamic Free Convective Flow past an Infinite Vertical Porous Plate
}

\author{
Nyundo Steven ${ }^{1}$, Gatheri K. Francis ${ }^{1}$, Sigey K. Johana ${ }^{2}$ \\ ${ }^{1}$ School of Mathematics and Statistics, The Kenya Polytechnic University College, Nairobi, Kenya \\ ${ }^{2}$ Department of Pure and Applied Mathematics, Jomo Kenyatta University of Agriculture and Technology, Nairobi, Kenya \\ Email: jksigey2002@yahoo.com, stevenyundo@yahoo.com,kgatheri@yahoo.com
}

Received April 19, 2912; revised May 30, 2012; accepted June 7, 2012

\begin{abstract}
A study of magnetic hydrodynamic free convective flow past an infinite vertical porous plate in an incompressible electrically conducting fluid is considered. The investigation of the effect of viscous dissipation on the velocity profiles and temperature distribution of the fluid in the presence of a transverse magnetic field subject to a constant suction velocity is conducted. The ordinary differential equations governing the flows are analyzed using an explicit finitedifference scheme and computer generated programs. The results are presented in graphical form showing the effects of the various parameters arising in the flow. The numerical results of the study show that an increase in the viscous dissipation causes an increase in the velocity profiles and temperature distribution of the fluid.
\end{abstract}

Keywords: Magnetic Hydrodynamic; Free Convection; Viscous Dissipation

\section{Introduction}

Magnetic hydrodynamics is the study of the interaction of electrically conducting fluids with magnetic fields. Viscous dissipation is the process by which the moving layers of an electrically conducting fluid produce internal fluid friction which offers resistance to the fluid flow. At low velocities the fluid tends to flow without lateral mixing, and adjacent layers slide past one another. As the velocity increases, the kinetic energy of the particles also increases leading to increase in temperature at a distance away from the plate.

The effect of applied variable magnetic field on unsteady free convection flow along a vertical plate has been given special interest because of its applications in the cooling of nuclear reactors or in the study of structures of stars and planets. Important engineering applications in which the study of MHD flows with variable magnetic fields includes power generators, heat exchangers, reactors and MHD accelerators among other devices.

The effect of retaining the viscous dissipation term in the energy equation in this work is analyzed. For the solution of the problem considered, the free-stream velocity, temperature and the induced magnetic field are oscillating in the time about constant mean values. The flow is subjected to a constant suction velocity, through the porous surface, and a magnetic field of uniform strength applied transversely to the direction of the flow. The influence of the various parameters entering into the problem is also extensively discussed signifying the importance of retaining the viscous dissipation term in the energy equation. A laminar flow, sometimes known as streamline flow, occurs when a fluid flows in parallel layers, with no disruption between the layers.

In laminar flow the motion of the particles of the fluid is very orderly with all particles moving in straight lines parallel to the fluid flow. In fluid dynamics, laminar flow is a flow regime characterized by high momentum diffusion and low momentum convection. When a viscous electrically conducting fluid flows in the presence of a transverse magnetic field, electromagnetic forces act on the fluid flowing. The momentum equation describing the motion of the fluid in the magnetic hydrodynamic flow includes body forces acting on the fluid particles from a distance. The applied magnetic field acts on the polarized fluid particles to produce the dynamic effect. As a result, when a viscous conducting fluid flows in the presence of a transverse magnetic field, the electromagnetic forces acting alter the geometry of their motion. This motion of the particles creates viscous dissipation in the fluid which affects the overall motion of the fluid.

Most engineering practical applications involve electrically conducting fluids with viscous dissipation. Viscous dissipation is of interest to many engineers for many applications: significant temperature rises are observed in polymer processing flows such as injection molding or 
extrusion at high rates. Aerodynamic heating in the thin boundary layer around high speed aircraft raises the temperature of the skin. In a completely different application, the dissipation function is used to define the viscosity of dilute suspensions. Geothermal gases are electrically conducting and are affected by the presence of a magnetic field.

The first research in magneto hydrodynamics was done by M. Faraday in 1931, [1] where he observed that a voltage was induced in a direction perpendicular to both the direction of the flow and the magnetic field, in his experiments on the behaviour or currents in circuits placed in time varying magnetic fields. Hartmann discussed both experimentally and theoretically the hydrodynamic magnetic flow. He discovered that applied magnetic field acts on both electronic and ionized atoms to produce the dynamic effect. H. M. Duwairi and A. Rabhi [2] analyzed viscous and joule heating effect on forced convection flow, where they observed that heat transfer rate is decreased due to viscous dissipation effect in both cases of suction or injection velocity in the fluid.

J. Z. Jordan [3] analyzed the effect of thermal radiation on MHD free convection flow over a semi-infinite vertical porous plate and he found that an increase in viscous dissipation leads to an increase in both velocity and temperature profiles. Ferdows et al. [4] analyses the dufor, soret and viscous dissipation effects on Heat and Mass Transfer in porous media with high porosities, while Kinyanjui et al. [5] studied MHD free convection heat and mass transfer of a heat generating fluid past an impulsively started infinite vertical porous plate with Hall current and radiation absorption.

Palani et al. [6] gave extensive analysis on MHD flow past a semi-infinite vertical plate with mass transfer, whereas, Tania et al. [7] studied the effect of radiation, heat generation and viscous dissipation on MHD free convection flow along a stretching sheet. In spite of all these contributions, the area of viscous dissipation past an infinite porous plate has received little attention from researchers.

\subsection{Definition of Terms}

\subsubsection{Mass Transfer}

Convection mass transfer involves the transport of materials between boundary surface and moving fluid. Mass transport always plays an important role in many industrial processes for example, removal of pollutants from plant discharge.

\subsubsection{Free Convection}

In Free convections, the fluid motion is as a result of density gradients created by temperature or concentration gradients existing in fluid.

\subsubsection{Viscous Dissipation}

Viscous dissipation is the process by which the moving layers of an electrically conducting fluid produce internal fluid friction which offers resistance to the fluid flow. At low velocities the fluid tends to flow without lateral mixing, and adjacent layers slide past one another. As the velocity increases, the kinetic energy of the particles also increases leading to increase in temperature at a distance away from the plate.

Viscosity also refers to the property of a fluid which determines its resistance to shearing stresses between the layers of a fluid. It is a measure of the internal fluid friction which causes resistance to the fluid flow. It is express mathematically as:

$$
\tau=\mu q
$$

where $q$ is the velocity of the fluid, $\mu$ is the coefficient of viscosity and $\tau$ is the shear stress. Fluids which obeys this relation are referred to as Newtonian fluids.

When an electrically conducting fluid flows, an increase in temperature leads to an increase in its kin-friction or viscosity. This viscosity increase could be along the $\mathrm{x}$-axis, the $\mathrm{y}$-axis or along the $\mathrm{z}$-axis. This phenomenon is called viscous dissipation. For a three-dimensional fluid the viscous dissipation term is expressed as:

$$
\phi=\left\{\left[\frac{\partial u}{\partial x}\right]^{2}+\left[\frac{\partial v}{\partial y}\right]^{2}+\left[\frac{\partial w}{\partial z}\right]^{2}\right\}-\left\{\frac{\partial u}{\partial y}+\frac{\partial v}{\partial z}+\frac{\partial w}{\partial x}\right\}^{2}
$$

this can be reduced into two dimensions to give:

$$
\phi=\left\{\left[\frac{\partial u}{\partial x}\right]^{2}+\left[\frac{\partial v}{\partial y}\right]^{2}\right\}-\left\{\frac{\partial u}{\partial y}+\frac{\partial v}{\partial x}\right\}^{2}
$$

When this term is simplified, the final form of the viscous dissipation term is:

$$
\phi=\left\{3\left[\frac{\partial u}{\partial x}\right]^{2}+2 \frac{\partial^{2} u}{\partial x \partial y}+3\left[\frac{\partial v}{\partial y}\right]^{2}\right\}
$$

\section{Geometry of the Problem}

In this case, we investigated the effect of viscous dissipation on a magnetic hydrodynamic free convective flow past an infinite vertical porous plate. The plate is parallel to the y-axis which is vertically placed normal to the $\mathrm{x}$-axis which is horizontal. A uniform magnetic field is applied in a direction normal to the porous plate. The flow configuration is illustrated in Figure 1.

\section{Specific Governing Equations}

In this work the unsteady two-dimensional free convective magnetic flow has been considered. The physical variables are functions of $x, y$ and $t$. The velocity com- 


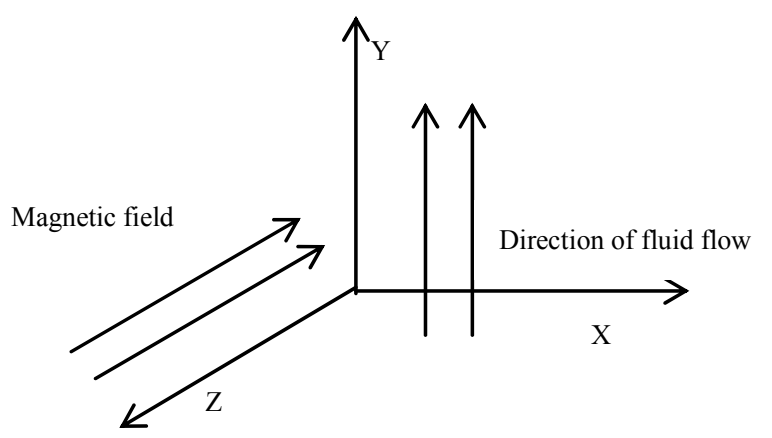

Figure 1. Geometry of the problem.

ponents in the $x$ and $y$ directions, are represented by $u$ and $v$ respectively.

The non-dimensionalized momentum equations in $x$ and $y$ directions respectively are:

$$
\begin{aligned}
& u_{(i, j)}^{n+1}=u_{(i, j)}^{n} u_{(i, j)}^{n} \\
& \cdot\left\{\left(\frac{u_{(i, j+1)}^{n}-u_{(i, j-1)}^{n}}{2 \Delta x}\right)+v_{(i, j)}^{n}\left(\frac{u_{(i+1, j)}^{n}-u_{(i-1, j)}^{n}}{2 \Delta y}\right)\right\} \Delta t
\end{aligned}
$$

and

$$
\begin{aligned}
& u_{(i, j)}^{n+1}=u_{(i, j)}^{n} u_{(i, j)}^{n} \\
& \cdot\left\{\left(\frac{u_{(i, j+1)}^{n}-u_{(i, j-1)}^{n}}{2 \Delta x}\right)+v_{(i, j)}^{n}\left(\frac{u_{(i+1, j)}^{n}-u_{(i-1, j)}^{n}}{2 \Delta y}\right)\right\} \Delta t \\
& +\left\{\frac{u_{(i, j+1)}^{n}-2 u_{(i, j)}^{n}+u_{(i, j-1)}^{n}}{(\Delta x)^{2}}+\frac{u_{(i+1, j)}^{n}-2 u_{(i, j)}^{n}+u_{(i-1, j)}^{n}}{(\Delta y)^{2}}\right. \\
& \left.+G r \theta_{(i, j)}^{n}+M^{2} \theta v_{(i, j)}^{n}\right\} \Delta t
\end{aligned}
$$

With initial conditions taken as:

$$
\begin{aligned}
& \text { for } x=0, u_{(0, j)}^{0}=1, v_{(0, j)}^{0}=0 . \\
& \text { for } x>0, u_{(0, j)}^{0}=1, v_{(0, j)}^{0}=0 .
\end{aligned}
$$

for $i>0$, and all $j$, the boundary conditions take the form;

$$
\begin{gathered}
\text { at } x=0, u_{(0, j)}^{n}=1, v_{(0, j)}^{0}=0 . \\
y=0, u_{(i, 0)}^{n}=1, v_{(i, 0)}^{0}=0 .
\end{gathered}
$$

The computations are performed using small values of $\Delta t$, In this work, we set $\Delta t=0.00125$

And $\Delta t=\Delta y=0.1$ We fixed $x=4.1$, that is $i=41$, as corresponding to $x=\infty$. Hence, we set $u_{(41, j)}^{n}=v_{(41, j)}^{n}=\theta_{(41, j)}^{n}=0$, because $u, u, \theta$ tend to zero around $x=4.1$. The procedure is repeated until $n=400$, that is $t=0.5$ for $i=1, x=0.1$. The non-dimensionalized energy equation for the flow is,

$$
\begin{aligned}
& \frac{\partial \theta}{\partial t}+u \frac{\partial \theta}{\partial t}=\frac{1}{\operatorname{Pr}}\left(\frac{\partial^{2} \theta}{\partial x^{2}}+\frac{\partial^{2} \theta}{\partial y^{2}}\right) \\
& +E c\left[3\left[\frac{\partial u}{\partial x}\right]^{2}+2 \frac{\partial^{2} u}{\partial x \partial y}+3\left[\frac{\partial u}{\partial y}\right]^{2}\right]
\end{aligned}
$$

and

$$
\begin{aligned}
& \frac{\partial \theta}{\partial t}+u \frac{\partial \theta}{\partial t}=\frac{1}{\operatorname{Pr}}\left(\frac{\partial^{2} \theta}{\partial x^{2}}+\frac{\partial^{2} \theta}{\partial y^{2}}\right) \\
& +E c\left[3\left[\frac{\partial v}{\partial x}\right]^{2}+2 \frac{\partial^{2} v}{\partial x \partial y}+3\left[\frac{\partial v}{\partial y}\right]^{2}\right]
\end{aligned}
$$

The two equations can be combined into one by introducing the viscous dissipation term, i.e.,

$$
\frac{\partial \theta}{\partial t}+u \frac{\partial \theta}{\partial t}=\frac{1}{\operatorname{Pr}}\left(\frac{\partial^{2} \theta}{\partial x^{2}}+\frac{\partial^{2} \theta}{\partial y^{2}}\right)+E c(\phi)
$$

These equations take the following form for their solutions:

$$
\begin{aligned}
& \left.\frac{\theta_{(i, j)}^{n+1}-\theta_{(i, j)}^{n}+u_{(i, j)}^{n}\left(\frac{\theta_{(i, j+1)}^{n}-\theta_{(i, j-1)}^{n}}{2 \Delta x}\right)}{\Delta t}\right) \\
& =\frac{1}{\operatorname{Pr}}\left(\frac{\theta_{(i+1, j)}^{n}-2 \theta_{(i, j)+}^{n} \theta_{(i-1, j)}^{n}}{(\Delta x)^{2}}\right) \\
& +\frac{1}{\operatorname{Pr}}\left(\frac{\theta_{(i, j+1)}^{n}-2 \theta_{(i, j)+}^{n} \theta_{(i, j-1)}^{n}}{(\Delta y)^{2}}\right) \\
& +E c 3\left\{\left(\frac{u_{(i, j+1)}^{n}-u_{(i, j-1)}^{n}}{2 \Delta x}\right)^{2}+2\left(\frac{u_{(i, j+1)}^{n}-2 u_{(i, j)+}^{n} u_{(i, j-1)}^{n}}{\Delta x \Delta y}\right)\right. \\
& \left.+3\left(\frac{u_{(i, j+1)}^{n}-u_{(i, j-1)}^{n}}{2 \Delta y}\right)^{2}\right\}
\end{aligned}
$$

and

$$
\begin{aligned}
& \frac{\theta_{(i, j)}^{n+1}-\theta_{(i, j)}^{n}}{\Delta t}+v_{(i, j)}^{n}\left(\frac{\theta_{(i, j+1)}^{n}-\theta_{(i, j-1)}^{n}}{2 \Delta y}\right) \\
& =\frac{1}{\operatorname{Pr}}\left(\frac{\theta_{(i, j+1)}^{n}-2 \theta_{(i, j)+}^{n} \theta_{(i, j-1)}^{n}}{(\Delta y)^{2}}\right)+\frac{1}{\operatorname{Pr}}\left(\frac{\theta_{(i+1, j)}^{n}-2 \theta_{(i, j)+}^{n} \theta_{(i-1, j)}^{n}}{(\Delta y)^{2}}\right) \\
& +E c 3\left\{\left(\frac{v_{(i+1, j)}^{n}-v_{(i-1, j)}^{n}}{2 \Delta x}\right)^{2}+2\left(\frac{v_{(i+1, j)}^{n}-2 v_{(i, j)+}^{n} u_{(i-1, j)}^{n}}{\Delta x \Delta y}\right)\right. \\
& \left.+3\left(\frac{v_{(i+1, j)}^{n}-v_{(i-1, j)}^{n}}{2 \Delta y}\right)^{2}\right\}
\end{aligned}
$$


or

$$
\begin{aligned}
& \left.\frac{\theta_{(i, j)}^{n+1}-\theta_{(i, j)}^{n}+v_{(i, j)}^{n}\left(\frac{\theta_{(i, j+1)}^{n}-\theta_{(i, j-1)}^{n}}{2 \Delta y}\right)}{\Delta t}\right) \\
& =\frac{1}{\operatorname{Pr}}\left(\frac{\theta_{(i, j+1)}^{n}-2 \theta_{(i, j)+}^{n} \theta_{(i, j-1)}^{n}}{(\Delta y)^{2}}\right) \\
& +\frac{1}{\operatorname{Pr}}\left(\frac{\theta_{(i+1, j)}^{n}-2 \theta_{(i, j)+}^{n} \theta_{(i-1, j)}^{n}}{(\Delta y)^{2}}\right) \\
& +E c(\phi)
\end{aligned}
$$

where $\operatorname{Ec}(\phi)$ is the viscous dissipation term.

The initial and boundary conditions in non-dimensional form are:

$$
\begin{aligned}
& \text { for } t \leq 0, u(x, y, 0)=0, v(x, y, 0)=0, \\
& \theta(x, y, 0)=0 \\
& t>0, u(0, y, t)=1, v(x, 0, t)=1 \\
& \theta(0, y, t)=1, \theta(x, 0, t)=1 \\
& \text { for } t>0, u(\infty, y, t)=0, v(x, \infty, t)=0 \\
& \theta(\infty, y, t)=0
\end{aligned}
$$

The initial conditions take the forms shown below:

$$
\begin{aligned}
& \text { at } x=0, u_{(0, j)}^{0}=1, v_{(0, j)}^{0}=0, \theta_{(0, j)}^{0}=1 \\
& \text { at } x>0, u_{(i, j)}^{0}=1, v_{(i, j)}^{0}=1, \theta_{(i, j)}^{0}=1
\end{aligned}
$$

The computations are performed using small values of $\Delta t$. In our computations, the Prandtl number is taken as 0.71 which corresponds to air, magnetic parameter $\mathrm{M}^{2}=5.0$, which signifies a strong magnetic field. We considered one case, that is when the $G r>0$, i.e. $(+0.4)$ corresponding to convective cooling of the plate.To ensure stability and convergence of the finite difference method, a computer program is run using smaller values of $\Delta t$ for instance, $\Delta t=0.0007,0.0005,0.0015$.

\section{Method of Solution}

The equations governing the free convective fluid flow in this study are non-linear, hence the finite difference method which is fast, consistent and stable has been used. This method is convergent since as more grid points were taken or step size decreased, the numerical solution converged to the exact solution. It is also stable, since the effect of any single fixed round off error was bounded. The finite difference method satisfies these basic requirements, hence was used.

In order to approximate the specific equations above by the explicit finite difference method, a suitable mesh with grid points well defined is applied. The mesh point was put on the $x-y$ plane with the horizontal axis representing
$\Delta x$ and the vertical axis $\Delta y$. The forward finite difference method for the first order time derivative and central finite difference for the first and second spatial derivatives, has been applied where the final set of the governing equation in the $x$ and $y$ directions are:

$$
\begin{aligned}
& \frac{u_{(i, j+1)}^{n}-u_{(i, j-1)}^{n}}{\Delta t}+u_{(i, j)}^{n}\left[\frac{u_{(i, j+1)}^{n}-u_{(i, j-1)}^{n}}{2 \Delta x}\right] \\
& +v_{(i, j)}^{n}\left[\frac{u_{(i, j+1)}^{n}-u_{(i, j-1)}^{n}}{2 \Delta y}\right] \\
& =\frac{v_{(i, j+1)}^{n}-2 u_{(i, j)}^{n}+v_{(i, j-1)}^{n}}{(\Delta x)^{2}} \\
& +\frac{v_{(i, j+1)}^{n}-2 u_{(i, j)}^{n}+v_{(i, j-1)}^{n}}{(\Delta y)^{2}}+G r \theta_{(i, j)}^{n}+M^{2} u_{(i, j)}^{n} \\
& v_{(i, j)}^{n+1}=v_{(i, j)}^{n} \\
& -\left\{u_{(i, j)}^{n}\left(\frac{v_{(i, j+1)}^{n}-v_{(i, j-1)}^{n}}{2 \Delta x}\right)+v_{(i, j)}^{n}\left(\frac{v_{(i+1, j)}^{n}-v_{(i-1, j)}^{n}}{2 \Delta y}\right) \Delta t\right\} \\
& +\left\{\frac{v_{(i, j+1)}^{n}-2 v_{(i, j)}^{n}+v_{(i, j-1)}^{n}}{(\Delta x)^{2}}+\frac{v_{(i+1, j)}^{n}-2 v_{(i, j)}^{n}+v_{(i-1, j)}^{n}}{(\Delta y)^{2}}\right. \\
& \left.+G r \theta_{(i, j)}^{n}+M^{2} v_{(i, j)}^{n}\right\} \Delta t
\end{aligned}
$$

The energy equation is represented by:

$$
\begin{aligned}
& \left(\frac{\theta_{(i, j+1)}^{n}-\theta_{(i-1, j)}^{n}}{2 \Delta y}\right)=\frac{1}{\operatorname{Pr}}\left(\frac{\theta_{(i, j+1)}^{n}-2 \theta_{(i, j)+}^{n} \theta_{(i, j-1)}^{n}}{(\Delta y)^{2}}\right) \\
& +\frac{1}{\operatorname{Pr}}\left(\frac{\theta_{(i+1, j)}^{n}-2 \theta_{(i, j)+}^{n} \theta_{(i-1, j)}^{n}}{(\Delta y)^{2}}\right)+E c(\phi)
\end{aligned}
$$

In these equations, $\Delta x=\Delta y=0.1$ and the computations were done for small values of $\Delta t$. In our case, we set $\Delta t=0.00125$.

In our computation again, the Prandtl number (ratio of viscous force to thermal forces) is taken as 0.71 . We considered one case, when the $G r>0$ (ratio of buoyancy forces to viscous forces) corresponding to convective cooling of the plate.

\section{Results}

The system of finite difference equations has been solved iteratively by use of a computer generated program. From the energy equation, it was observed that the viscous dissipation term comprised of the Eckert number. Since the Eckert number is a constant scalar multiple of the viscous dissipation, its increase leads to the increase in the viscous dissipation term. 
To plot the graphs for the velocity, and temperature with values of Eckert number varying from 0 - 1 the iterations have been performed for $n=0,1,2 \cdots, 200$, where $n$ is the number of iterations performed as shown in Table 1. As the Eckert number varied, the viscous dissipation term also changed. The results have been presented in Tables 1 and 2, Figures 2 and 3.

In Figure 2, the velocity profiles remained constant for some given distance $\times(50$ units $)$ away from the plate before increasing. For each Eckert number, the graphs increased to a maximum and then remained constant.

Table 2 represents part of our computer generated temperature results. We noted that for each value of the Eckert number or viscous dissipation parameter, the results obtained in the table were similar for the first 50 iterations.

In Figure 3, the temperature profile remained constant from the plate up to a distance $\times(50$ units $)$ before increasing. It was noted that for each Eckert number, the graphs increased to a maximum and then remained constant.

\section{Discussion}

An analysis of the effect of viscous dissipation on a magnetic hydrodynamic free convective flow past an infinite vertical porous plate has been carried out. In all the cases considered, the velocity was resolved in two components and the work was restricted to the laminar boundary layer. In this case the Grash of number, $G r>0$, implying that the temperature of the plate was greater than that of the fluid in the free stream region hence heat was transferred from the plate to the fluid which led to the convective cooling of the plate by free convection currents.

However, the heat was not sufficient enough for the fluid particles to acquire a high velocity at the region near the plate. Thus, the velocity of the moving fluid particles remained constant for some time as shown in Figure 2, before gaining enough kinetic energy, from the collisions of the fluid particles. Once the particles had gained maximum kinetic energy, we found out that the graph remained constant, for each value of the viscous dissipation parameter, or Eckert number. This explained the shapes of the velocity graphs obtained.

For each value of the viscous dissipation parameter, we noted that as the fluid flowed, the particles gained kinetic energy, leading to the increased collisions of the fluid particles which led to a rise in temperature. This rise continued until a point was reached where the increase in the collisions did not result in any temperature change, thus the graphs remained constant as shown in Figure 3.

\section{Conclusion}

In conclusion, this study has therefore asserted that anin-
Table 1. Velocity profiles.

\begin{tabular}{ccccc}
\hline \multicolumn{5}{c}{ VELOCITY, U } \\
\hline & $\mathbf{I}$ & II & III & IV \\
\hline 0 & 0 & 0 & 0 & 0 \\
1 & $3.82 \mathrm{E}-101$ & $3.82 \mathrm{E}-101$ & $3.82 \mathrm{E}-101$ & $3.82 \mathrm{E}-101$ \\
2 & $1.31 \mathrm{E}-99$ & $1.31 \mathrm{E}-99$ & $1.31 \mathrm{E}-99$ & $1.31 \mathrm{E}-99$ \\
3 & $2.24 \mathrm{E}-98$ & $2.24 \mathrm{E}-98$ & $2.24 \mathrm{E}-98$ & $2.24 \mathrm{E}-98$ \\
4 & $2.54 \mathrm{E}-97$ & $2.54 \mathrm{E}-97$ & $2.54 \mathrm{E}-97$ & $2.54 \mathrm{E}-97$ \\
5 & $2.16 \mathrm{E}-96$ & $2.16 \mathrm{E}-96$ & $2.16 \mathrm{E}-96$ & $2.16 \mathrm{E}-96$ \\
6 & $1.47 \mathrm{E}-95$ & $1.47 \mathrm{E}-95$ & $1.47 \mathrm{E}-95$ & $1.47 \mathrm{E}-95$ \\
7 & $8.36 \mathrm{E}-95$ & $8.36 \mathrm{E}-95$ & $8.36 \mathrm{E}-95$ & $8.36 \mathrm{E}-95$ \\
8 & $4.09 \mathrm{E}-94$ & $4.09 \mathrm{E}-94$ & $4.09 \mathrm{E}-94$ & $4.09 \mathrm{E}-94$ \\
9 & $1.76 \mathrm{E}-93$ & $1.76 \mathrm{E}-93$ & $1.76 \mathrm{E}-93$ & $1.76 \mathrm{E}-93$ \\
10 & $6.74 \mathrm{E}-93$ & $6.74 \mathrm{E}-93$ & $6.74 \mathrm{E}-93$ & $6.74 \mathrm{E}-93$ \\
11 & $2.34 \mathrm{E}-92$ & $2.34 \mathrm{E}-92$ & $2.34 \mathrm{E}-92$ & $2.34 \mathrm{E}-92$ \\
12 & $7.47 \mathrm{E}-92$ & $7.47 \mathrm{E}-92$ & $7.47 \mathrm{E}-92$ & $7.47 \mathrm{E}-92$ \\
13 & $2.20 \mathrm{E}-91$ & $2.20 \mathrm{E}-91$ & $2.20 \mathrm{E}-91$ & $2.20 \mathrm{E}-91$ \\
14 & $6.04 \mathrm{E}-91$ & $6.04 \mathrm{E}-91$ & $6.04 \mathrm{E}-91$ & $6.04 \mathrm{E}-91$ \\
15 & $1.56 \mathrm{E}-90$ & $1.56 \mathrm{E}-90$ & $1.56 \mathrm{E}-90$ & $1.56 \mathrm{E}-90$ \\
16 & $3.79 \mathrm{E}-90$ & $3.79 \mathrm{E}-90$ & $3.79 \mathrm{E}-90$ & $3.79 \mathrm{E}-90$ \\
17 & $8.75 \mathrm{E}-90$ & $8.75 \mathrm{E}-90$ & $8.75 \mathrm{E}-90$ & $8.75 \mathrm{E}-90$ \\
18 & $1.92 \mathrm{E}-89$ & $1.92 \mathrm{E}-89$ & $1.92 \mathrm{E}-89$ & $1.92 \mathrm{E}-89$ \\
19 & $4.05 \mathrm{E}-89$ & $4.05 \mathrm{E}-89$ & $4.05 \mathrm{E}-89$ & $4.05 \mathrm{E}-89$ \\
20 & $8.19 \mathrm{E}-89$ & $8.19 \mathrm{E}-89$ & $8.19 \mathrm{E}-89$ & $8.19 \mathrm{E}-89$ \\
\hline & & & &
\end{tabular}

Table 2. Temperature distributions.

\begin{tabular}{ccccc}
\hline \multicolumn{5}{c}{ TEMPERATURE, T } \\
\hline & I & II & III & IV \\
\hline 0 & 0 & 0 & 0 & 0 \\
1 & $3.82 \mathrm{E}-101$ & $3.81 \mathrm{E}-101$ & $3.81 \mathrm{E}-101$ & $3.81 \mathrm{E}-101$ \\
2 & $1.30 \mathrm{E}-99$ & $1.30 \mathrm{E}-99$ & $1.30 \mathrm{E}-99$ & $1.30 \mathrm{E}-99$ \\
3 & $2.22 \mathrm{E}-98$ & $2.22 \mathrm{E}-98$ & $2.22 \mathrm{E}-98$ & $2.22 \mathrm{E}-98$ \\
4 & $2.52 \mathrm{E}-97$ & $2.52 \mathrm{E}-97$ & $2.52 \mathrm{E}-97$ & $2.51 \mathrm{E}-97$ \\
5 & $2.13 \mathrm{E}-96$ & $2.13 \mathrm{E}-96$ & $2.13 \mathrm{E}-96$ & $2.13 \mathrm{E}-96$ \\
6 & $1.45 \mathrm{E}-95$ & $1.45 \mathrm{E}-95$ & $1.45 \mathrm{E}-95$ & $1.45 \mathrm{E}-95$ \\
7 & $8.19 \mathrm{E}-95$ & $8.19 \mathrm{E}-95$ & $8.19 \mathrm{E}-95$ & $8.19 \mathrm{E}-95$ \\
8 & $3.99 \mathrm{E}-94$ & $3.99 \mathrm{E}-94$ & $3.99 \mathrm{E}-94$ & $3.99 \mathrm{E}-94$ \\
9 & $1.71 \mathrm{E}-93$ & $1.71 \mathrm{E}-93$ & $1.71 \mathrm{E}-93$ & $1.71 \mathrm{E}-93$ \\
10 & $6.52 \mathrm{E}-93$ & $6.52 \mathrm{E}-93$ & $6.52 \mathrm{E}-93$ & $6.52 \mathrm{E}-93$ \\
11 & $2.26 \mathrm{E}-92$ & $2.26 \mathrm{E}-92$ & $2.26 \mathrm{E}-92$ & $2.26 \mathrm{E}-92$ \\
12 & $7.16 \mathrm{E}-92$ & $7.16 \mathrm{E}-92$ & $7.16 \mathrm{E}-92$ & $7.16 \mathrm{E}-92$ \\
13 & $2.10 \mathrm{E}-91$ & $2.10 \mathrm{E}-91$ & $2.10 \mathrm{E}-91$ & $2.10 \mathrm{E}-91$ \\
14 & $5.74 \mathrm{E}-91$ & $5.74 \mathrm{E}-91$ & $5.74 \mathrm{E}-91$ & $5.74 \mathrm{E}-91$ \\
15 & $1.47 \mathrm{E}-90$ & $1.47 \mathrm{E}-90$ & $1.47 \mathrm{E}-90$ & $1.47 \mathrm{E}-90$ \\
16 & $3.57 \mathrm{E}-90$ & $3.57 \mathrm{E}-90$ & $3.57 \mathrm{E}-90$ & $3.57 \mathrm{E}-90$ \\
17 & $8.19 \mathrm{E}-90$ & $8.19 \mathrm{E}-90$ & $8.19 \mathrm{E}-90$ & $8.19 \mathrm{E}-90$ \\
18 & $1.79 \mathrm{E}-89$ & $1.79 \mathrm{E}-89$ & $1.79 \mathrm{E}-89$ & $1.79 \mathrm{E}-89$ \\
19 & $3.76 \mathrm{E}-89$ & $3.76 \mathrm{E}-89$ & $3.75 \mathrm{E}-89$ & $3.75 \mathrm{E}-89$ \\
20 & $7.55 \mathrm{E}-89$ & $7.55 \mathrm{E}-89$ & $7.55 \mathrm{E}-89$ & $7.55 \mathrm{E}-89$ \\
\hline & & & &
\end{tabular}




\section{GRAPH OF VELOCITY, U WITH Ec VARYING}

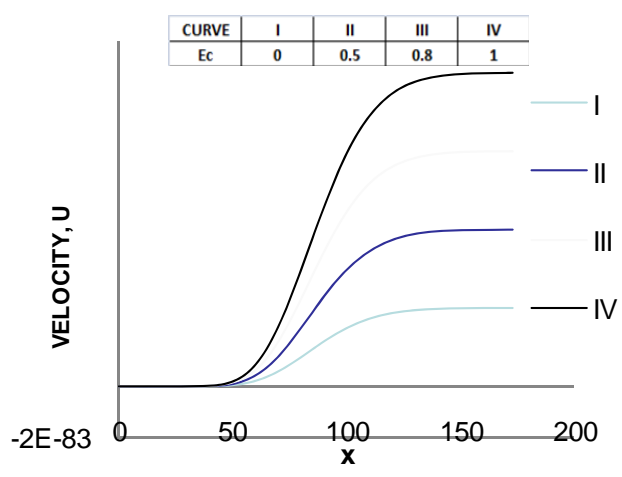

Figure 2. Graph of primary velocity profile.

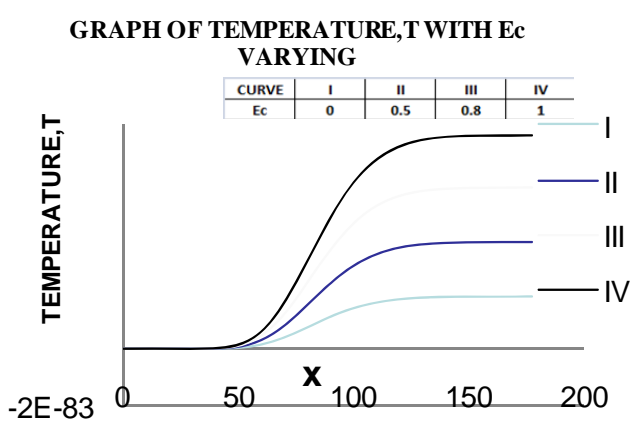

Figure 3. Graph of temperature distribution.

crease in the viscous dissipation parameter or term leads to an increase in velocity and temperature profiles. This increase in the velocity profiles and temperature profile occurred at a distance away from the porous plate.

\section{REFERENCES}

[1] M. Faraday, "Electricity Researches in Electricity," 1st Series Philosophical Transactions of the Royal Society, 1831, pp. 125-162.

[2] H. M. Duwairi and A. Rablhi, "Fluid over a Vertical Surface," International Journal of Fluid Mechanics, Vol. 32, No. 1, 2005, pp. 81-87. doi:10.1615/InterJFluidMechRes.v32.i3.10

[3] J. Z. Jordan, "Network Simulation Method Applied to Radiation and Viscous Dissipation Effects on MHD Unsteady Free Convection over Vertical Porous Plate," Applied Mathematical Modeling, Vol. 31, 2007, pp. 20192033. doi:10.1016/j.apm.2006.08.004

[4] M. Ferdows, K. Kaino and C. H. Chen, "Dufor, Soret and Viscous Dissipation Effects on Heat and Mass Transfer in Porous Media with High Porosities," International Journal of Applied Engineering Research, Vol. 5, No. 3, 2010, pp. 477-484.

[5] N. M. Kinyanjui, J. K. Kwanza and S. M. Uppal, "MHD Free Convection Heat and Mass Transfer of a Heat Generating Fluid Past an Impulsively Started Infinite Vertical Porous Plate with Hall Current and Radiation Absorption," Energy Conversion and Management, Vol. 42, 2001, pp. 917-931. doi:10.1016/S0196-8904(00)00115-1

[6] G. Palani and U. Srikanth, "MHD Flow past a Semi Infinite Vertical Plate with Mass Transfer," Non-Linear Analysis: Modeling and Control, Vol. 4, No. 3, 2009, pp. 345-356.

[7] S. K. Tania and M. A. Samad, "Effects of Radiation Heat Generation and Viscous Dissipation on MHD Free Convection Flow along a Stretching Sheet," Research Journal of Applied Sciences Engineering and Technology, Vol. 2, No. 4, 2010, pp. 368-377. 